\title{
Correction to: Olaratumab in Combination with Doxorubicin for the Treatment of Advanced Soft Tissue Sarcoma: An Evidence Review Group Perspective of a National Institute for Health and Clinical Excellence Single Technology Appraisal
}

Irina A. Tikhonova ${ }^{1}$ Tracey Jones-Hughes ${ }^{1} \cdot$ James Dunham $^{1} \cdot$ Fiona C. Warren ${ }^{1}$. Sophie Robinson $^{1} \cdot$ Peter Stephens $^{2} \cdot$ Martin Hoyle $^{1}$

Published online: 24 February 2018

(C) Springer International Publishing AG, part of Springer Nature 2018

Correction to: PharmacoEconomics (2018) 36:39-49

https://doi.org/10.1007/s40273-017-0568-3

Page 41, Column 1, Section 3.1, paragraph 2, 1st sentence which

Previously read:

"In patients who had no prior lines of therapy for advanced disease, an investigator-assessed improvement in median progression-free survival (PFS) was 2.5 months (6.6 months, 95\% confidence interval [CI] 4.1-8.3) in the OlaDox arm versus 4.1 months (95\% CI 2.8-5.4) in the doxorubicin arm (hazard ratio [HR] $0.672 ; p=0.0615$ ) [8]."

Should read:

"In patients who had no prior lines of therapy for advanced disease, an investigator-assessed improvement in median progression-free survival (PFS) for OlaDox was 2.5 months [6.6 months (95\% CI 3.1-9.3) in the OlaDox arm versus 4.1 months (95\% CI 2.8-6.2) in the doxorubicin arm (hazard ratio $[\mathrm{HR}]=0.771 ; p=0.2842$ )] [7]."

The original article can be found online at https://doi.org/10.1007/ s40273-017-0568-3.

Irina A. Tikhonova

I.Tikhonova@exeter.ac.uk

1 Peninsula Technology Assessment Group (PenTAG), Exeter, UK

2 Royal Devon and Exeter NHS Foundation Trust, Exeter, UK 